World Applied Sciences Journal 7 (12): 1552-1558, 2009

ISSN 1818-4952

(C) IDOSI Publications, 2009

\title{
The Effect of Moisture and Temperature on Thermophysical Properties of Iranian Pistachios
}

\author{
${ }^{1}$ Ahmad Kouchakzadeh and ${ }^{2}$ Teymur Tavakoli \\ ${ }^{1}$ Department of Agri Machinery Engineering, Ilam University, Ilam, Iran \\ ${ }^{2}$ Department of Agri Machinery, Tarbyat Modaress University, Tehran, Iran
}

\begin{abstract}
Thermal conductivity, Thermal diffusivity and bulk density of pistachios were measured at temperature ranging from 50 to $93^{\circ} \mathrm{C}$ and moisture content ranging from 3 to $52 \%(\mathrm{db})$. The line heat source method was employed to determine thermal conductivity and diffusivity. Specific heats were calculated from measured thermal conductivity, diffusivity and bulk density. Decreases in moisture content to $11.5 \%(\mathrm{db})$ produce reduction in thermal conductivity and specific heat, but decreases in moisture content to $3.3 \%(\mathrm{db})$, cause proportional increases in thermal conductivity and specific heat. Average values of thermal conductivity and specific heat were changed from 0.231 to $0.466 \mathrm{~W} / \mathrm{m}^{\circ} \mathrm{C}$ and from 1894 to $3820 \mathrm{~J} / \mathrm{Kg}^{\circ} \mathrm{C}$ in different moisture content, respectively.
\end{abstract}

Key word: Bulk thermal conductivity . bulk thermal diffusivity . bulk density . specific heat . line heat source method. Iran pistachio

\section{INTRODUCTION}

Over the past fifty years, the production of pistachio (Pistachio Vera 1.) in central Iran has increased dramatically so that it is now about 380000 hectares and produces annually 350000 tons of pistachios. (DIA.2007). Iran is the most important pistachio exporter.

The pistachios moisture at harvesting time is about 40 to $50 \%$ dry basis according to date and climatic location. However, for storage and consumption pistachios need to dry 5 to $7 \%$. Rate of drying pistachios in free air is slowly and needs 2 or 3 days period that produce conditions in with fungus growth. So pistachios dryers are needed where pistachios in bulk expose hot air at temperatures 50 to $93^{\circ} \mathrm{C}$ for 3 to 8 hours. Huge amount of fossil fuels is being burned annually in these dryers. (MIC.2007). In Iran, these dryers consume approximately three million litters of mostly diesel fuel each year. Knowledge of thermal properties is important in the solution of these problems. In addition, processing operations on pistachios involve heat transfer. Therefore, information on thermal properties is required.

The objective of the investigation reported in this paper was to determine the thermal conductivity, thermal diffusivity and density of pistachio over a wide range of temperature and moisture conditions then values of specific heat were calculated from the relationship:

$$
\mathrm{c}=\frac{\mathrm{k}}{\alpha \rho}
$$

The thermal conductivity of various kinds of grain has been determined in a number of ways. Early investigators used one dimension, steady-state heat flow methods. There are two disadvantages to these methods. a-it takes several hours to conduct each test and b-moisture migration that occurs as the material approaches steady state conditions will produce erroneous results with moist materials. From the fundamental equations it can be shown that transient heat flow in an infinite cylinder of homogeneous material, initially heated by a line heat source may be expressed as:

$$
\begin{gathered}
\mathrm{T}=\frac{\mathrm{Q}}{2 \pi \mathrm{k}} \int_{\beta}^{\infty} \frac{\exp \left(-\mathrm{x}^{2}\right) \mathrm{dx}}{\mathrm{x}} \\
\beta=\mathrm{r} / 2 \sqrt{\alpha \theta}
\end{gathered}
$$

where, this equation can be transformed and expanded to an infinite series. If $\beta$ is smaller than 0.16 the temperature change between the times $\theta_{2}, \theta_{1}$ can be expressed by the first two terms of the series as:

$$
\mathrm{T}_{2}-\mathrm{T}_{1}=\frac{\mathrm{Q}}{4 \pi \mathrm{k}} \ln \left(\frac{\theta_{2}}{\theta_{1}}\right)
$$


To compensate for the mass and size of the heating element, plot $d \mathrm{~T} / \mathrm{d} \theta$ versus time and obtain a value for the time correction $\theta_{0}$ at $\mathrm{dT} / \mathrm{d} \theta=0$. Equation (3) with the time correction value then becomes:

$$
\mathrm{T}_{2}-\mathrm{T}_{1}=\frac{\mathrm{Q}}{4 \pi \mathrm{k}} \ln \left(\frac{\theta_{2}-\theta_{0}}{\theta_{1}-\theta_{0}}\right)
$$

Moysey et al. (1977) converted the time correction value to:

$$
\theta_{0}=\theta_{1} \exp \left(\frac{\mathrm{T}^{0}-\mathrm{A}}{\mathrm{B}}\right)
$$

where, $\theta_{1}=$ A reference time chosen after the temperature time curve becomes linear. $\mathrm{A}$ and $\mathrm{B}=$ Constants for a least squares fit to a natural $\log$ function. $\mathrm{T}^{0}=$ Initial temperature minus reference temperature at time $\theta_{1}$

In the actual test apparatus, the heat source is finite in length and the sample is finite in diameter, the error produced by assuming axial flow mathematically. For the apparatus used in these tests, substitution into equations suggests that the error due to the assumption of axial flow is less than one tenth of 1 percent.

Nix et al. (1969) developed an iteration technique to obtain values of thermal conductivity and thermal diffusivity from a single test. To utilize equation (2) to solve for thermal diffusivity it is expanded to an infinite series:

$$
\mathrm{T}=\frac{\mathrm{Q}}{2 \pi \mathrm{k}}\left[\frac{-\mathrm{C}_{\mathrm{e}}}{2}-\ln \beta-\sum_{\mathrm{n}=1}^{\infty} \frac{(-1)^{\mathrm{n}}\left(\beta^{2}\right)^{\mathrm{n}}}{(2 \mathrm{n})(\mathrm{n} !)}\right]
$$

$\beta$ is as previously defined. $\beta$ is found by the NewtonRaphson iteration technique. Stark, (1970), Rao et al. (1975), Singh, P and D.R. Heldman. (1993). and $\alpha$ is then calculated for known values of $r, \theta$ and $\beta$. Suter et al. (1975) and used this approach in determining the thermal properties of peanut pods, hulls and kernels.

Hsu et al. (1991) evaluated physical and thermal properties of pistachios at room temperature. The method of line heat source was employed to determine thermal conductivity and diffusivity but specific heats were measured by method of mixture. Bulk pistachios with apparent mass and temperature throw a Calorimeter full of water with known specific heat. Then pistachios specific heat was calculated by changing the temperature of water, also the specific heat of Iranian pistachio nuts was measured by Razavi, S and Taghizadeh, M. (2007) for initial moisture content, 25, 15 and 5\% w.b. and temperature 25, 40, 55 and $70^{\circ} \mathrm{C}$. with this method.

No information about thermophysical properties of pistachios at temperatures that confines in drying process with line heat source method was found.

Pistachios used in this study were of Iranian cultivar, obtained from pistachio producers of Rafsanjan located in Kerman province, Iran, during the 2007 harvest season.

\section{MATERIALS AND METHODS}

The apparatus used for the thermal conductivity and thermal diffusivity tests consisted of a hollow stainless steel tube $200 \mathrm{~mm}$ in diameter and $400 \mathrm{~mm}$ long. A 300 watt, 220-volt tungsten-alloy heating wire with $180 \mathrm{~mm}$ length sheathes in a cupper tube

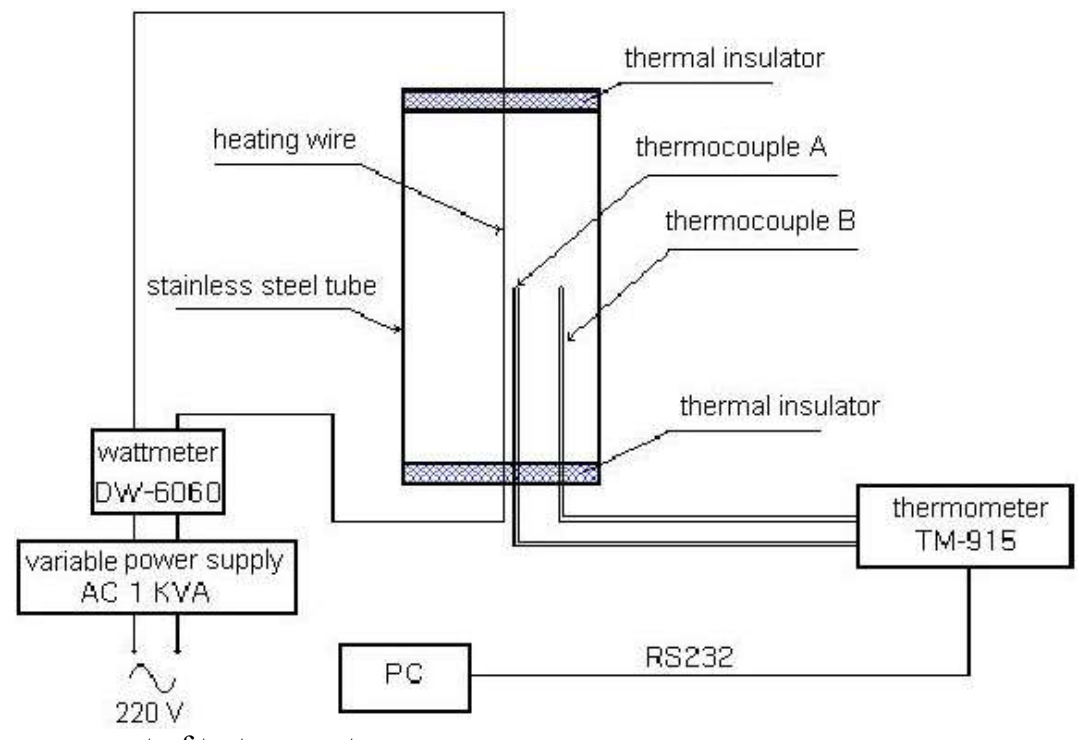

Fig. 1: Schematic arrangement of test apparatus 
with $6 \mathrm{~mm}$ diameter and $300 \mathrm{~mm}$ long installed in the axis of the cylinder. Wire temperature was controlled by changing the wire voltage with a $1 \mathrm{KVA}$ AC variable power supply. Wattage was read from a LUTRON DW-6060 digital wattmeter in series with the heater with resolution of 1 watt. Temperature was measured midway along the heating wire using two $\mathrm{k}$ type thermocouple wire (Fig. 1). This thermocouples were kept parallel in 18 and $40 \mathrm{~mm}$ distance from the to the line heat source.

The potential of the thermocouple circuit was measured by a LUTRON TM-915 two-channel thermometer with RS-232 output to USB port and a resolution of $1^{\circ} \mathrm{C}$. Temperature readings were recorded on a computer with SW-U001 ver 1.3 software. After temperature of thermocouple A (Fig. 1) was constant, the temperature history of thermocouple B (Fig. 1) $40 \mathrm{~mm}$ from the line source was used to determine the thermal diffusivity.

The bulk density of samples was determined by filling a $1091 \mathrm{ml}$ graduate and weighing at room temperature. An attempt was made to fill the graduate in the same manner as the container used for the thermal conductivity and diffusivity tests. Results reported are the average of 6 tests.

All of the tests were conducted on the abasali and khani variety of pistachio. The samples obtained from an orchard in Iran, Kerman province during harvesting season in September 2008.

Initial moisture content of the pistachios was about 40 to 50 percent dry basis. Samples of about $10 \mathrm{~kg}$ each were conditioned either by drying in an oven to obtain different levels of moisture content ranging from about 3.3 percent to 51.5 percent dry basis. The moisture content was determined by oven drying according to a standard method (ASAE, 2005). Recorded data computed with Matlab ver 7 software.

\section{RESULTS AND DISCUSSION}

Bulk density: Results of the bulk density tests are shown in Fig. 2. The density of khani pistachios increases from 422.6 to $574.1 \mathrm{Kg} / \mathrm{m}^{3}$ at 4.3 to $52.8 \%$ moisture content (d.b.) respectively. But density of abasali pistachios rises from 417 to $542.9 \mathrm{Kg} / \mathrm{m}^{3}$ at 3.3 to $51.5 \%$ moisture content (d.b.) respectively. Linear regression equation was determined for the data with $\mathrm{R}^{2}=99.93$ as:

$$
\rho=411+289 M
$$

From Hsu et al. (1991) work the liner model for bulk density of California pistachio at $20^{\circ} \mathrm{C}$ for the moisture wet basis term was:

$$
\rho=439+500.3 \mathrm{M}
$$

An $\mathrm{F}$ test on the derivative data from equations 7 and 8 showed that there was insignificant difference at the 5 percent level between them.

\section{THERMAL CONDUCTIVITY}

The model of thermal conductivity versus temperature in $51.5 \%$ moisture content is an exponential but in $31.2 \%$ is a quadratic. At first thermal conductivity increases as temperature rises, then after 70 to $80^{\circ} \mathrm{C}$ approach descent. In this level of moisture content process of releasing moisture from surface and drying of pistachios have constant rate. In lower moisture as 20, 11.5 and $3.3 \%$ dry basis thermal conductivity cause to move in the opposite direction of temperature. In this level of moisture content drying process have descend rate commonly. Average values of thermal conductivity at 50 to $93^{\circ} \mathrm{C}$ were changed from 0.231 to $0.466 \mathrm{~W} / \mathrm{m}^{\circ} \mathrm{C}$ in different moisture content. Polynomial regression equations were determined for the data with $\mathrm{R}^{2}>0.95$ as follows:

$$
\begin{gathered}
\mathrm{k}=-5427.82+10703.87 \exp \left(\frac{1}{\mathrm{~T}}\right) \\
-5276.85 \exp \left(\frac{2}{\mathrm{~T}}\right) \quad \mathrm{M}=51.5 \% \\
\mathrm{k}=-2.1+0.064 \mathrm{~T}-0.0004 \mathrm{~T}^{2} \quad \mathrm{M}=31.2 \% \\
\frac{1}{\mathrm{k}}=0.234+0.034 \mathrm{~T} \quad \mathrm{M}=20 \% \\
\frac{1}{\mathrm{k}}=0.43+0.032 \mathrm{~T} \quad \mathrm{M}=11.5 \% \\
\frac{1}{\mathrm{k}}=0.265+0.047 \mathrm{~T} \quad \mathrm{M}=3.3 \%
\end{gathered}
$$

Results of the thermal conductivity are shown in Fig. 3 for $51.5 \%$, Fig. 4 for $31.2 \%$, Fig. 5 for $20 \%$, Fig. 6 for $11.5 \%$ and Fig. 7 for $3.3 \%$ moisture contents.

\section{THERMAL DIFFUSIVITY}

Thermal diffusivity of pistachios reduces at higher temperature but differences are low. Differences of thermal diffusivity at 55 to $95^{\circ} \mathrm{C}$ in any moisture content are under $0.01 \mathrm{~cm}^{2} / \mathrm{sec}$. Average values of thermal diffusivity at previously mentioned temperatures were changed from minimum $0.0293 \times 10^{-7} \mathrm{~m}^{2} / \mathrm{sec}$ to maximum $4.385 \times 10^{-7} \mathrm{~m}^{2} / \mathrm{sec}$ on 


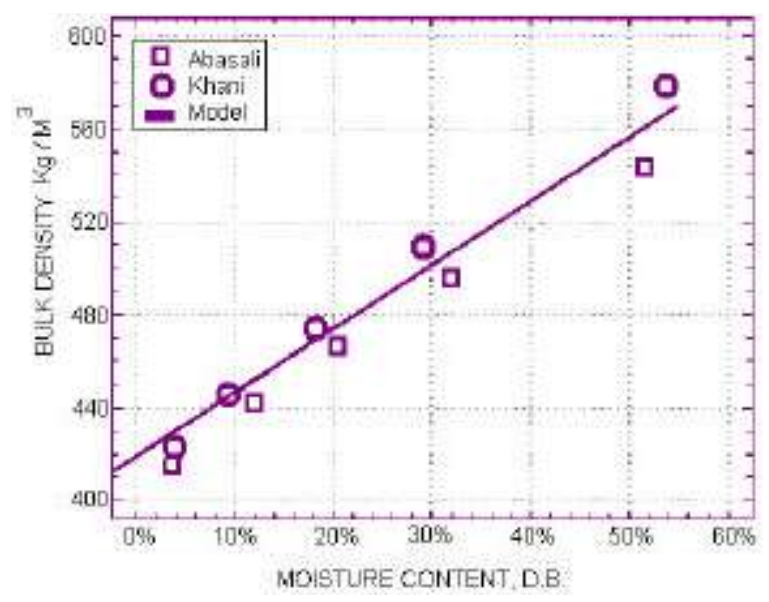

Fig. 2: Effect of moisture content on bulk density of pistachio

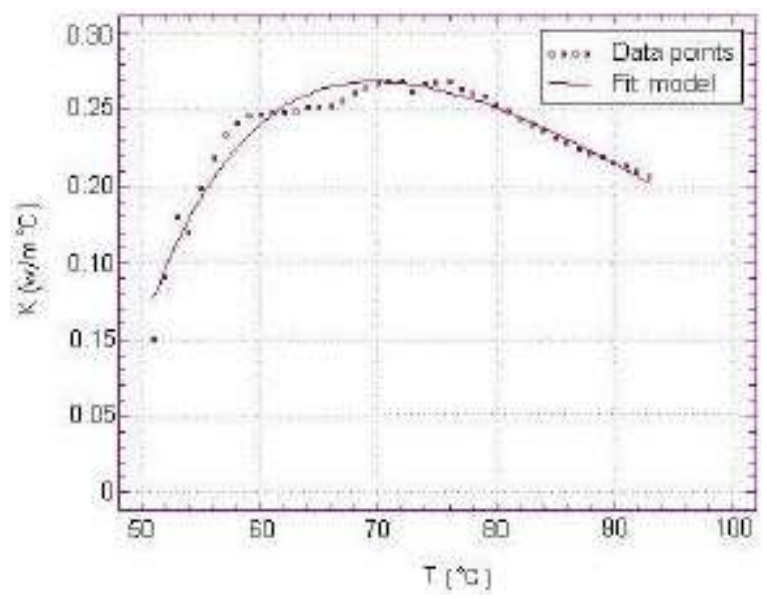

Fig. 3: Thermal conductivity vs. temperature in 51.5\% moisture content

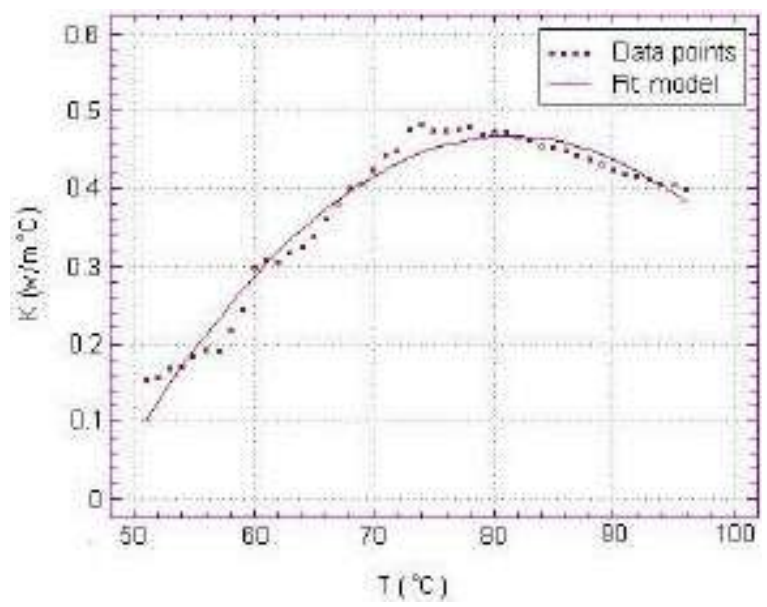

Fig. 4: Thermal conductivity vs. temperature in $31.2 \%$ moisture content

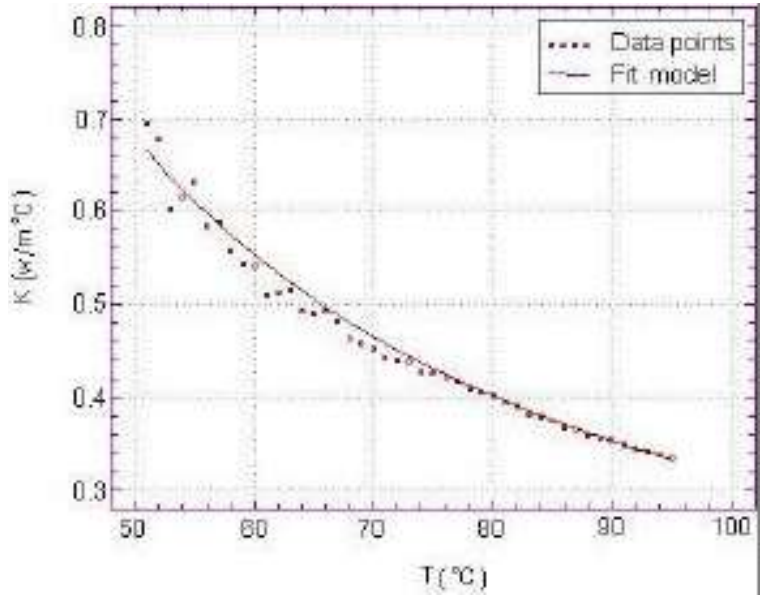

Fig. 5: Thermal conductivity vs. temperature in $20 \%$ moisture content

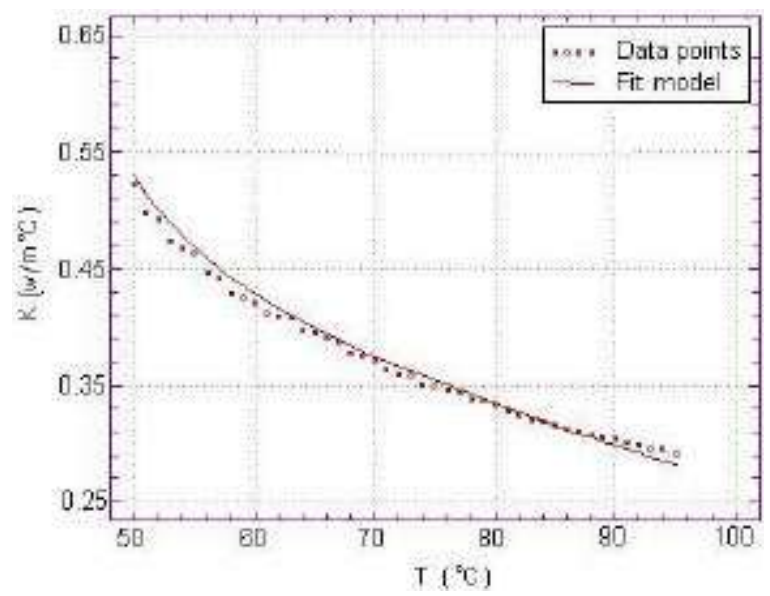

Fig. 6: Thermal conductivity vs. temperature in $11.5 \%$ moisture content

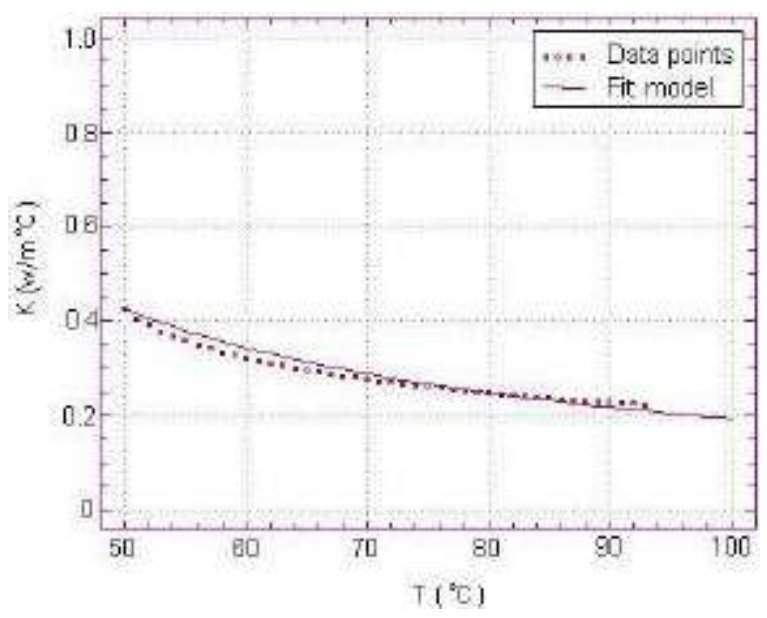

Fig. 7: Thermal conductivity vs. temperature in $3.3 \%$ moisture content 


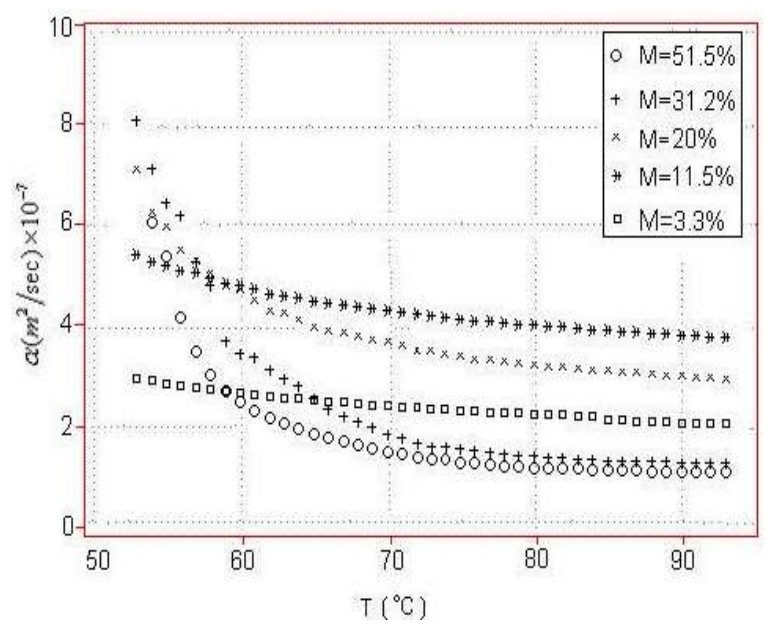

Fig. 8: Thermal diffusivities vs. temperature in various moistures

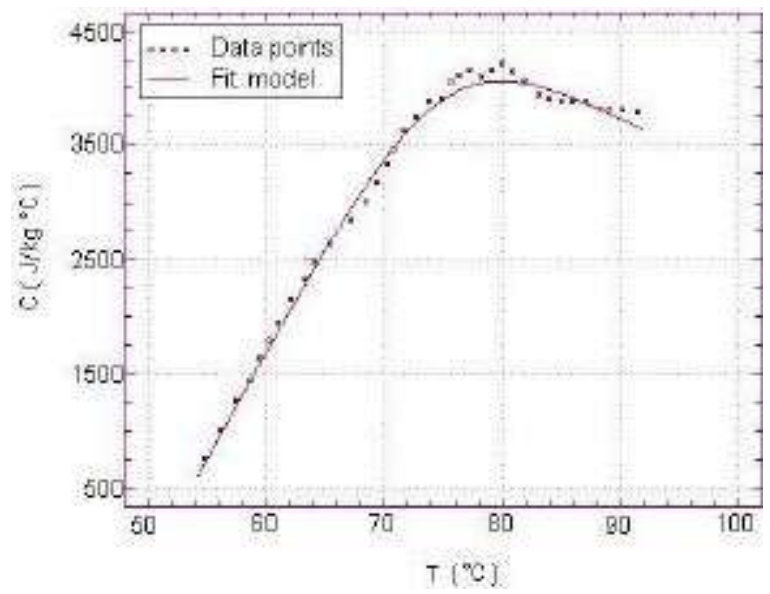

Fig. 9: Specific heat vs. temperature in 51.5\% moisture content

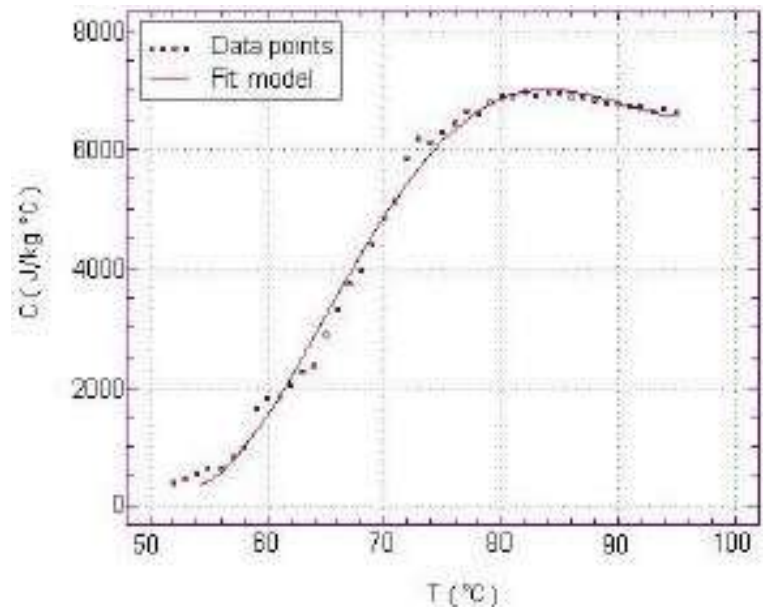

Fig. 10: Specific heat vs. temperature in $31.2 \%$ moisture content

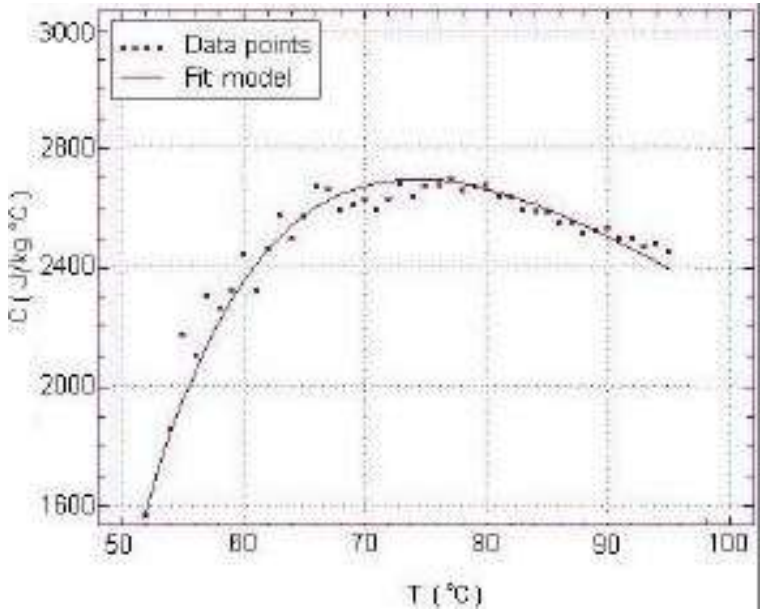

Fig. 11: Specific heat vs. temperature in $20 \%$ moisture content

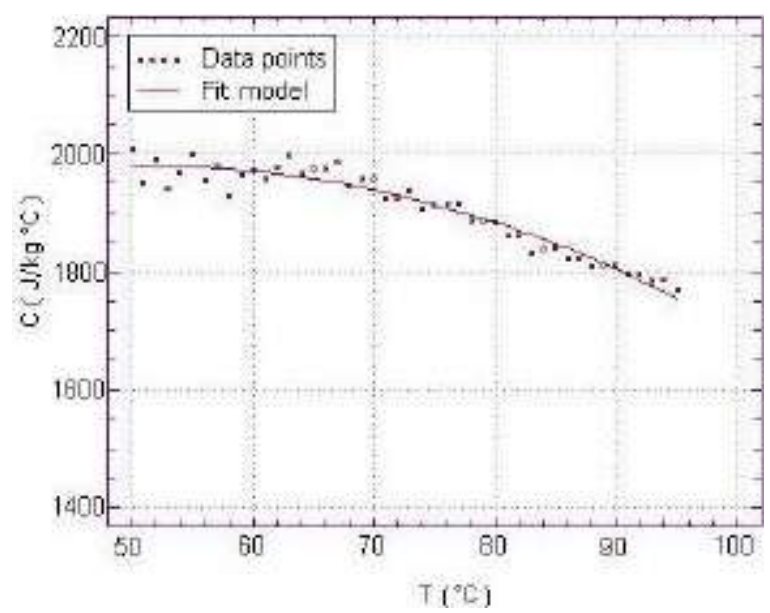

Fig. 12: Specific heat vs. temperature in $11.5 \%$ moisture content

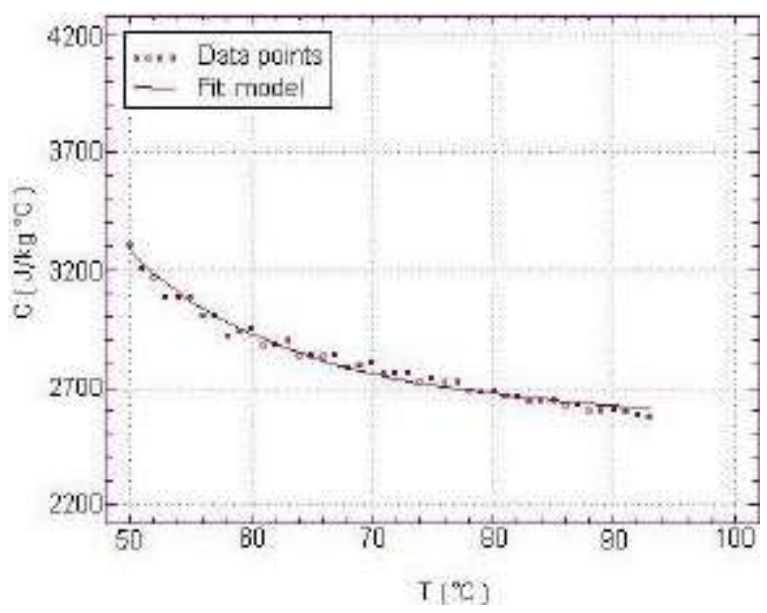

Fig. 13: Specific heat vs. temperature in 3.3\% moisture content 
various moisture content. Polynomial regression equations were determined for the data with $\mathrm{R}^{2}>0.89$, all thermal diffusivity are converse function versus temperature as follows:

$$
\begin{aligned}
& \frac{1}{\alpha}=-8311460+205178 \mathrm{~T} \quad M=51.5 \% \\
& \frac{1}{\alpha}=-7956650+183085 \mathrm{~T} \quad \mathrm{M}=31.2 \% \\
& \frac{1}{\alpha}=-1012020+50101.6 \mathrm{~T} \quad \mathrm{M}=20 \% \\
& \frac{1}{\alpha}=799010+20961.9 \mathrm{TM}=11.5 \% \\
& \frac{1}{\alpha}=1649090+35375 \mathrm{~T} \quad \mathrm{M}=3.3 \%
\end{aligned}
$$

Results of the thermal diffusivity are shown in Fig. 8.

\section{SPECIFIC HEAT}

It is obviously showed that bulk pistachios specific heat increases at similar temperatures with reduction moisture content on $31.2 \%$, then in lower moisture content the specific heat decreases at same temperatures but in $3.3 \%$ moisture content rises again. Average values of specific heats at 50 to $93^{\circ} \mathrm{C}$ were changed from minimum 1894 to maximum $3820 \mathrm{~J} / \mathrm{kg}^{\circ} \mathrm{C}$ on various moisture content. Polynomial regression equations were determined for the data with $\mathrm{R}^{2}>0.97$ as follows:

$$
\begin{gathered}
\mathrm{c}=-25292.68+707.023 \mathrm{~T}-4.2576 \mathrm{~T}^{2} \quad \mathrm{M}=51.5 \% \\
\mathrm{c}=376092.7-21410.09 \mathrm{~T}+442.0305 \mathrm{~T}^{2} \\
-3.91237 \mathrm{~T}^{3}+0.012639 \mathrm{~T}^{4} \quad \mathrm{M}=31.2 \% \\
\mathrm{c}=-33770560+66641420 \exp \left(\frac{1}{\mathrm{~T}}\right) \\
-32874220 \exp \left(\frac{2}{\mathrm{~T}}\right) \mathrm{M}=20 \% \\
\mathrm{c}=1653.91+12.47 \mathrm{~T}-0.1199 \mathrm{~T}^{2} \mathrm{M}=11.5 \% \\
\mathrm{c}=2530.41+659441200 \mathrm{~T} / 5 \quad \mathrm{M}=3.3 \%
\end{gathered}
$$

Results of the specific heats are shown in Fig. 9 for 51.5\%, Fig. 10 for $31.2 \%$, Fig. 11 for 20\%, Fig. 12 for $11.5 \%$ and Fig. 13 for $3.3 \%$ moisture contents.

\section{DISCUSSION}

The line heat source method was used to determine thermal conductivity and diffusivity. Specific heats were calculated from measured thermal conductivity, diffusivity and bulk density.

Our results showed that the specific heats of pistachios were changed from 1.894 to $3.820 \mathrm{~kJ} / \mathrm{kg}^{\circ} \mathrm{C}$ in different moisture content, Moisture content. The study of Razavi, S and Taghizadeh, M. (2007) for initial moisture content, 25, 15 and 5\% w.b. and temperature $25,40,55$ and $70^{\circ} \mathrm{C}$. with method of mixture showed that the range of $0.419-2.930 \mathrm{~kJ} / \mathrm{kg}^{\circ} \mathrm{C}$, however, the effect of moisture content was greater than both variety and temperature.

For bulk pistachios in 51.5 and $31.2 \%$ moisture content, the thermal conductivity increases when temperature rises, then after 70 to $80^{\circ} \mathrm{C}$ approaches to descent. In this level of pistachios moisture content

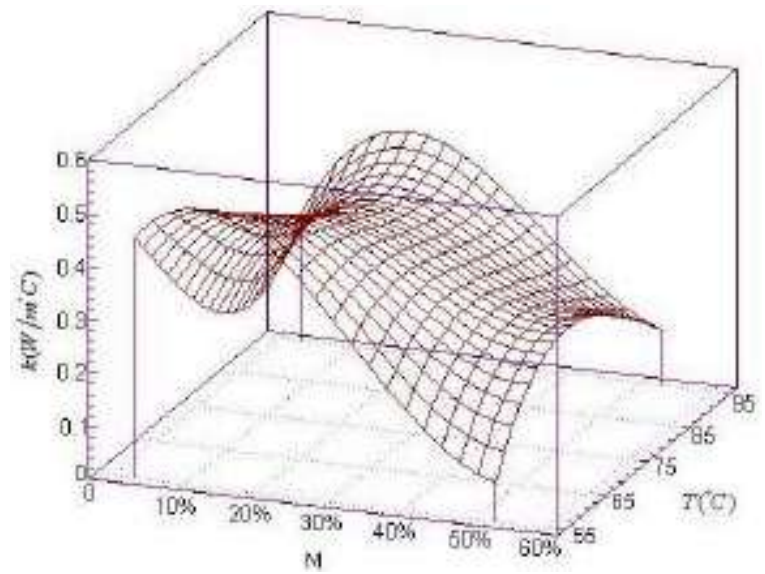

Fig. 14: Thermal conductivities of pistachios vs. temperature and moisture content

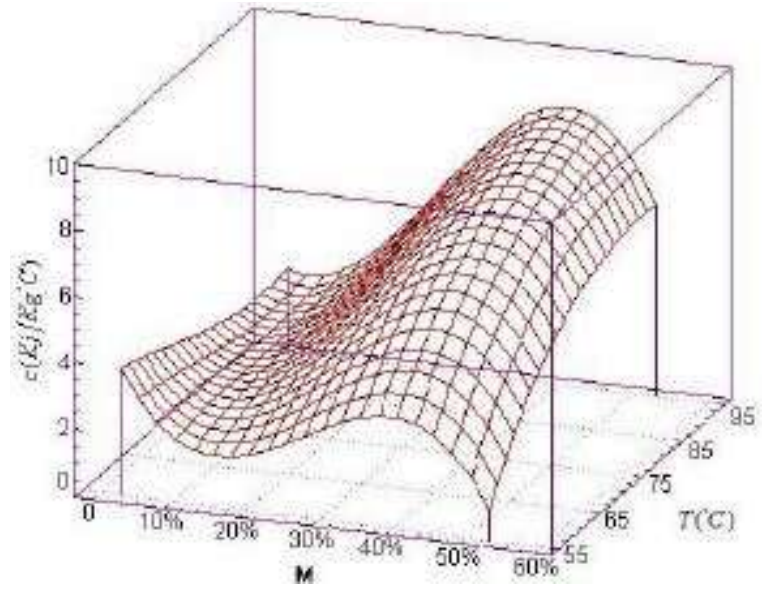

Fig. 15: Specific heats of pistachios vs. temperature and moisture content 
drying process are in phase 1 and in lower moisture such as 20, 11.5 and $3.3 \%$ thermal conductivity moves in the opposite direction of temperature. In this level of pistachios moisture content drying process are in phase 2.

For the results, bulk specific heat and thermal conductivity were determined as function of temperature and moisture by multiple regressions as:

$$
\begin{gathered}
\mathrm{k}=-8.066769 \mathrm{M}+0.05493 \mathrm{~T}-8.5956 \mathrm{M}^{2} \\
-0.001284 \mathrm{~T}^{2}+0.271137 \mathrm{MT} \\
+10.622738 \mathrm{M}+\left(7.590181 \times 10^{-6}\right) \mathrm{T}^{3} \\
-0.037529 \mathrm{M}^{2} \mathrm{~T}-0.001569 \mathrm{~T}^{2} \mathrm{M} \\
\mathrm{R}^{2}=95.17 \\
\mathrm{c}=-150559.3 \mathrm{M}+387.87837 \mathrm{~T}+283301.6 \mathrm{M}^{2} \\
-7.46351 \mathrm{~T}^{2}+2315.373851 \mathrm{MT} \\
-281406.5 \mathrm{M}^{3}+0.038866 \mathrm{~T}^{3} \\
-947.32602 \mathrm{M}^{2} \mathrm{~T}-10.165614 \mathrm{~T}^{2} \mathrm{M} \\
\mathrm{R}^{2}=95.11
\end{gathered}
$$

Equations (24) and (25) are valid for temperatures between 50 to $93^{\circ} \mathrm{C}$ and moistures between 3 to $53 \%$ dry basis. Results are shown in Fig. 14 and 15.

\section{ACKNOWLEDGMENTS}

The authors gratefully acknowledge the Astan Ghods Razavi Pistachio terminal Rafsanjan, Iran.

Nomenclature

\begin{tabular}{ll}
\hline $\mathrm{C}:$ & Specific heat $\left(\mathrm{J} / \mathrm{kg}^{\circ} \mathrm{C}\right)$ \\
Q: & Heat input $(\mathrm{W} / \mathrm{m})$ \\
$\alpha:$ & Thermal diffusivity $\left(\mathrm{m}^{2} / \mathrm{s}\right)$ \\
$\mathrm{r}:$ & Distance from heat source $(\mathrm{m})$ \\
$\mathrm{k}:$ & Thermal conductivity $\left(\mathrm{W} / \mathrm{m}^{\circ} \mathrm{C}\right)$ \\
$\theta:$ & Heating time $(\mathrm{s})$ \\
$\rho:$ & Density $\left(\mathrm{kg} / \mathrm{m}^{3}\right)$ \\
$\mathrm{C}_{\mathrm{e}}:$ & Euler's constant $(0.5772157)$ \\
$\mathrm{M}:$ & Moisture content $(\mathrm{dry}$ basis $)$ \\
$\theta_{2}, \theta_{1}, \theta_{0}:$ Time $(\mathrm{sec})$ \\
$\mathrm{T}: \quad$ Temperature field $\left({ }^{\circ} \mathrm{C}\right)$ \\
$\mathrm{n}: \quad$ Positive integers \\
$\mathrm{T}^{0}:$ Initial temperature $\left({ }^{\circ} \mathrm{C}\right)$ \\
$\mathrm{x}: \quad$ Dummy variable \\
$\beta: \quad$ Dimensionless \\
\hline
\end{tabular}

\section{REFERENCES}

1. ASAE, 2005. Standard for measurement of moisture in grain and seed. Agri. Eng. Yearbook of 2005. ASAE, pp: 564.

2. DIA, 2007. (Data and Information Administration.)Agricultural Statistic Collection; Ministry of Jahad Agriculture of Iran. Dept. of Budget and Programming, Tehran, Iran.

3. Hooper, F.C. and A.R. Lepper, 1950. Transient heat flow apparatus for determination thermal conductivity. Transaction of American Society of Heating and Ventilating Engineers, 56: 309-324.

4. Hsu, M.H., J.D. Mannapperuma and R.P. Singh, 1991. Physical and thermal properties of pistachios. Journal of Agricultural Engineering Research, 49 (6): 311-321.

5. MIC, 2007. (Momtazan Industrial Co.) Kerman, Iran.

6. Moysey, E.B, J.T. Shaw and W.P. Lampman, 1977. The effect of temperature and moisture on the thermal properties of rapeseed. Transactions of the ASAE, pp: 461-464.

7. Nix, G.H., R.I. Vachon, G.W. Lowery and I.A. McCurry, 1969. The line source method. Plenum Press. New York.

8. Rao, M.A., J. Barnard and J.F. Kenny, 1975. Thermal conductivity and thermal diffusivity of process variety squash and white potato. Transactions of the ASAE, pp: 1188-1192.

9. Razavi, S.M.A. and M. Taghizadeh, 2007. The specific heat of pistachio nuts as ffected by moisture content, temperature and variety. Journal of Food Engineering, 79: 158-167.

10. Singh, P. and D.R. Heldman, 1993. Introduction to food engineering. Second Edition. Academic Press, Inc. San Diego, California.

11. Standard No. 4920. Pistachio Test Methods; Standard and Industrial Research Inst. Press, Iran, 1999.

12. Suter, D.A., K.K. Agrawal and B.L. Clary, 1975. Thermal properties of peanut pods and kernels. Transactions of ASAE, pp: 370-375. 